\title{
Clozapine Preferentially Increases Dopamine Release in the Rhesus Monkey Prefrontal Cortex Compared with the Caudate Nucleus
}

Kenneth D. Youngren, B.S., Fiona M. Inglis, Ph.D., Philip J. Pivirotto, B.S., Hank P. Jedema, M.S., Charles W. Bradberry, Ph.D., Patricia S. Goldman-Rakic, Ph.D., Robert H. Roth, Ph.D., and Bita Moghaddam, Ph.D.

Despite substantial differences between species in the organization and elaboration of the cortical dopamine innervation, little is known about the pharmacological response of cortical or striatal sites to antipsychotic medications in nonhuman primates. To examine this issue, rhesus monkeys were chronically implanted with guide cannulae directed at the principal sulcus, medial prefrontal cortex, premotor cortex, and caudate nucleus. Alterations in dopamine release in these discrete brain regions were measured in response to administration of clozapine or haloperidol. Clozapine produced significant and longlasting increases in dopamine release in the principal sulcus, and to a lesser extent, in the caudate nucleus. Haloperidol did not produce a consistent effect on dopamine release in the principal sulcus, although it increased dopamine release in the caudate. Clozapine's preferential augmentation of dopamine release in the dorsolateral prefrontal cortex supports the idea that clozapine exerts its therapeutic effects in part by increasing cortical dopamine neurotransmission. [Neuropsychopharmacology 20: 403-412, 1999] (c) 1999 American College of Neuropsychopharmacology. Published by Elsevier Science Inc.
KEY WORDS: Antipsychotic drugs; Microdialysis;

Schizophrenia; Striatum; Haloperidol

The atypical antipsychotic drug clozapine (Clozaril) displays a unique clinical profile among drug therapies for schizophrenia. It is effective at alleviating psychosis in patients whose illness does not respond to typical antipsychotic drug therapies such as haloperidol (Haldol) and chlorpromazine (Thorazine) (Kane et al. 1988).

From the Interdepartmental Neuroscience Program (KDY), Department of Psychiatry (FMI, HPJ, CWB, RHR, BM), Department of Pharmacology (RHR), and Section of Neurobiology (PJP, PSG-R, BM), Yale University School of Medicine, New Haven, Connecticut.

Address correspondence to: Bita Moghaddam, Ph.D., Department of Psychiatry, Yale University School of Medicine, VA Medical Center 116A/2, West Haven, CT 06516.

Received March 25, 1998; revised July 13, 1998; accepted August 3, 1998 .
Clozapine rarely produces extrapyramidal side effects, such as tardive dyskinesia, associated with classic neuroleptic treatment (Kane et al. 1993), and it may alleviate the negative symptomatology of schizophrenia (Kane et al. 1988; Lee et al. 1994).

Traditionally, the property of antipsychotic drugs that correlates most closely with clinical efficacy is their ability to act as antagonists at the dopamine $\mathrm{D}_{2}$ receptor subtype (Creese et al. 1977). However, clozapine displays a relatively low affinity for the $\mathrm{D}_{2}$ receptor (Seeman et al. 1976) and also for the $D_{1}$ receptor (Machida et al. 1992) despite its superlative clinical effects. Among dopamine receptors, clozapine shows a much higher affinity and preference for the $\mathrm{D}_{4}$ receptor (van Tol et al. 1991).

Clozapine's unique clinical profile may relate to a regional specificity of action. In fact, clozapine and haloperidol have distinct effects on dopaminergic neurotransmission in the rodent brain, which may relate to 
the two drugs' differing therapeutic profiles. Acute systemic administration of clozapine increases dopamine release to a greater extent in the prefrontal cortex than in subcortical areas (Moghaddam and Bunney 1990; Pehek et al. 1993). Also, chronic treatment with clozapine increases the resting extracellular dopamine concentration in the medial prefrontal cortex (Yamamoto and Cooperman 1994; Youngren et al. 1994). In contrast, acute haloperidol preferentially increases subcortical dopamine release, and chronic treatment with haloperidol is without effect on the extracellular concentration of dopamine in the prefrontal cortex (Yamamoto and Cooperman 1994).

The neurochemical evidence described above was obtained entirely from studies conducted in rodents. Important differences in the dopaminergic innervation of the rodent and primate cortex (Berger et al. 1991) and the evolution of new areas of prefrontal cortex in primates (Preuss and Goldman-Rakic 1991) warrant the investigation of antipsychotic drug effects in the primate brain. Thus, in the enlarged, regionally specialized primate frontal lobe, we sought to determine whether responses to antipsychotic drugs are conserved between species.

Accordingly, the present study examined the effects of acute antipsychotic drug treatment on extracellular concentrations of dopamine in discrete cortical and subcortical brain regions in the rhesus monkey. For this purpose, we developed a chronic implant technique, similar to that of Kolachana et al. (1994), that allowed us to make repeated measures over two or more years. This enabled the comparison of the effects of acute clozapine and haloperidol on neurotransmitter levels in dorsolateral prefrontal cortex, medial prefrontal cortex, premotor cortex, and caudate nucleus, all of which are locations of dopamine terminal fields.

\section{MATERIALS AND METHODS}

\section{Subjects}

Three young adult male rhesus macaque monkeys (Macaca mulatta) weighing between 8 and $14 \mathrm{~kg}$ were used. Monkeys were housed individually with a 12-h light/dark cycle. Food and water were available ad libitum. Care and use of the animals were in strict compliance with the National Institutes of Health Guide for the Care and Use of Laboratory Animals (1987). For each monkey, the interval between two same drug studies was a minimum of 5 weeks, with the interval often being longer. The interval between two different drug studies within a subject was a minimum of 10 weeks. Over the two or more years of experimentation that these subjects underwent, no major systemic or local infections developed due to the chronic implants. The subjects displayed good overall health throughout the experimental period.

\section{Magnetic Resonance Imaging}

Magnetic resonance (MR) imaging was employed to produce a stereotaxic map of each animal according to the methods of Wang et al. (1990). MR imaging was performed using a General Electric Signa MR (Milwaukee, WI) unit operating at 1.5 Tesla. Images were obtained in three planes using a spoiled-gradient echo sequence with a repetition time of $25 \mathrm{~ms}$, and an echo time of 6 ms. Slice thickness was $1 \mathrm{~mm}$. The field of view was 14 $\mathrm{cm}$ with two excitations with 128 phase encode steps. Images were constructed using a 2-dimensional Fourier transform and were displayed in a $256 \times 192$ matrix with a pixel size of $0.55 \mathrm{~mm} \times 0.73 \mathrm{~mm}$.

Each animal was restrained initially with ketamine (5-10 mg/kg I.M.) and atropine sulfate (0.2 mg/ $\mathrm{kg}$ I.M.), then anesthetized with sodium pentobarbital (10-15 $\mathrm{mg} / \mathrm{kg}$ I.V.), and placed in a custom-made stereotaxic instrument constructed of MR-compatible fiberglass laminate resin. A custom-made tooth marker was aligned with amalgam fillings previously attached to the animal's maxillary dentitia, and measurements were recorded in three planes to accurately reposition the animal in the stereotaxic instrument at the time of surgery. Coordinates for intended target sites were determined using the image analysis software provided with the MR unit. Anterior-posterior measurements were made by determining the distance between the reference points (mineral oil) in the ear bars and the target site, as seen on coronal images. Left-right measurements were made by determining the distance between the target site and the midline of the brain, as seen on coronal images.

Guide cannulae for microdialysis probes consisted of 19 gauge thin-wall stainless steel tubing (Small Parts, Miami Lakes, FL) glued into the base of black nylon plug/receptacle assemblies (Newark Electronics, Windsor, CT). Each base provided two parallel rows of cannulae (either $5+4$ or $9+8$ ) with a total number of 9 or 17 cannulae, respectively, per base. Cannulae were 1.25 $\mathrm{mm}$ in diameter and $2.5 \mathrm{~mm}$ center-to-center apart. Rows of cannulae were $2.2 \mathrm{~mm}$ center-to-center apart. These cannula assemblies were outfitted with removable nylon tops with 23 gauge stainless steel wire stylets (22 $\mathrm{mm}$ length) glued in place. Individual stylets kept the cannulae patent between procedures on a given animal. Assemblies containing 9 cannulae were used bilaterally to target the principal sulcus. Assemblies containing 17 cannulae were used bilaterally to target the medial prefrontal and premotor cortices, as well as deeper structures, such as the caudate nucleus and putamen.

\section{Surgery}

All surgery, implanting of guide cannulae, and microdialysis procedures were carried out under aseptic 
conditions. For surgery, animals were restrained with ketamine and atropine, as above, and anesthetized with sodium pentobarbital (10-15 $\mathrm{mg} / \mathrm{kg}$ I.V. initially) for the duration of the procedure. The animal was placed in the same custom-made stereotaxic instrument used in MR imaging. For each cannula implantation site, a trephine was used to make the initial opening. Rongeurs then were used to enlarge the opening to the size appropriate for the guide assembly to be used. Guide cannula assemblies were fixed to the skull using dental acrylic cement and stainless steel skull screws. Blunt-tip stainless steel wires were placed into each guide cannula and marked at the entry point to the cannula to determine, for each cannula, a measurement of the distance from the top of the cannula to dura mater. Implant tops with stainless steel wire stylets were then fixed to each implant base using fixed bolts and removable nuts.

\section{Microdialysis Procedure}

Before each microdialysis session, animals were restrained with ketamine and atropine, as above; then isoflurane gas anesthesia (1.5-2.0\%) was administered. Animals were intubated and placed in a stereotaxic instrument. Implant top assemblies were removed, and the guide cannulae were exposed. Stainless steel needles (22 or 23 gauge) were used to puncture the dura mater over individual probe target sites. Sterile concentric dialysis probes, with an outer diameter of $330 \mu \mathrm{m}$, and an exposed membrane tip of $2.5-3.5 \mathrm{~mm}$ in length were used. Probes were not tested for in vitro recovery. In most experimental sessions, five microdialysis probes were used: Four probes targeted the prefrontal cortical regions and were distributed between the two hemispheres. In one hemisphere, one probe targeted the principal sulcus, while another probe targeted the medial prefrontal cortex. In the other hemisphere, one probe targeted the principal sulcus, while another probe targeted the premotor cortex. In one of the hemispheres, one probe also targeted the caudate nucleus or the putamen. Probes were perfused with artificial cerebrospinal fluid (145 mM NaCl, $2.7 \mathrm{mM} \mathrm{KCl}, 1.2 \mathrm{mM} \mathrm{CaCl}_{2}$, and $1.0 \mathrm{mM} \mathrm{MgCl} 2)$. All solutions passed through a $0.2 \mu \mathrm{m}$ syringe filter (Gelman Sciences, Ann Arbor, MI) before entering the microdialysis probe. Once probes were in position within the brain, they were perfused continuously at a rate of $2 \mu \mathrm{L} / \mathrm{min}$. After $1 \mathrm{~h}$, sample collection began. Samples were collected every $20 \mathrm{~min}$ and frozen on dry ice until assay by high performance liquid chromatography with electrochemical detection (HPLC-EC). Samples were assayed for dopamine on the same day. Dopamine content in dialysis samples was determined by HPLC-EC as described in Moghaddam et al. (1993). Measurable baseline concentrations of dopamine were not always obtained from every probe site. This may have been due to probe placement and, at times, was due to probe malfunction or breakage. At any point during an experiment, when flow through a probe was compromised, the probe was disconnected, and no further dialysis was performed through that probe.

After a minimum of $2 \mathrm{~h}$ of baseline collections, clozapine $(2.0 \mathrm{mg} / \mathrm{kg}$ I.V.) or haloperidol $(0.5 \mathrm{mg} / \mathrm{kg}$ I.V.) was administered. Clozapine was dissolved in a minimum amount of $0.1 \mathrm{~N} \mathrm{HCl}$, and this solution was added to sterile injectable saline. Then $0.1 \mathrm{~N} \mathrm{NaOH}$ was added to this solution to raise the $\mathrm{pH}$ to approximately 6.0-6.5. Sterile injectable haloperidol (McNeil Pharmaceuticals, Spring House, PA) was diluted in an equal volume of sterile injectable saline. Drug solutions were injected I.V. using a $0.2-\mu \mathrm{m}$ syringe filter as above. Following drug administration, sample collection continued for a minimum of $2 \mathrm{~h}$. Throughout microdialysis procedures, the animal's breathing, heart rate, EKG, core temperature, and concentration of anesthesia were monitored.

\section{Sacrifice and Histology}

At the time of sacrifice (2 to 3 years after surgical implantation), each animal was restrained with ketamine and atropine as above and then given an overdose ( $\sim 30-40 \mathrm{mg} / \mathrm{kg}$ I.V.) of sodium pentobarbital. The animal was then perfused with saline followed by $4 \%$ paraformaldehyde, and the brain was removed. Later, the brain was blocked and prepared for histology.

Postmortem analysis of coronal sections $(40 \mu \mathrm{m}$ thickness) of the rhesus monkey brain stained with cresyl violet for probe placement verification demonstrated clear probe tracks extending into all brain regions targeted, both cortical and subcortical areas. In this example (Figure 1), the probe track extends along the ventral bank of the principal sulcus.

Figure 2A shows the exterior of the left hemisphere of the brain from one subject. The blackened dots aligned in two parallel rows over the banks of the principal sulcus (Walker's area 46) represent the locations of cannula/probe implantation sites. The coronal MR image (Figure 2B) shows how the two banks of the principal sulcus were targeted for cannula implantation. An example of the guide cannulae used is shown in Figure 2C.

\section{Data Analysis}

The effects of drug treatment in each region were determined through the use of one-way repeated measures ANOVA applied to the absolute concentrations of dopamine (fmol $/ \mu \mathrm{L}$ dialysate, not corrected for in vitro recovery). Significant main effects were analyzed further by using the Tukey posthoc comparison of means. To examine differences between brain regions, the data were $\log$ transformed to reduce variance due to different baseline dopamine concentrations, and two-way re- 


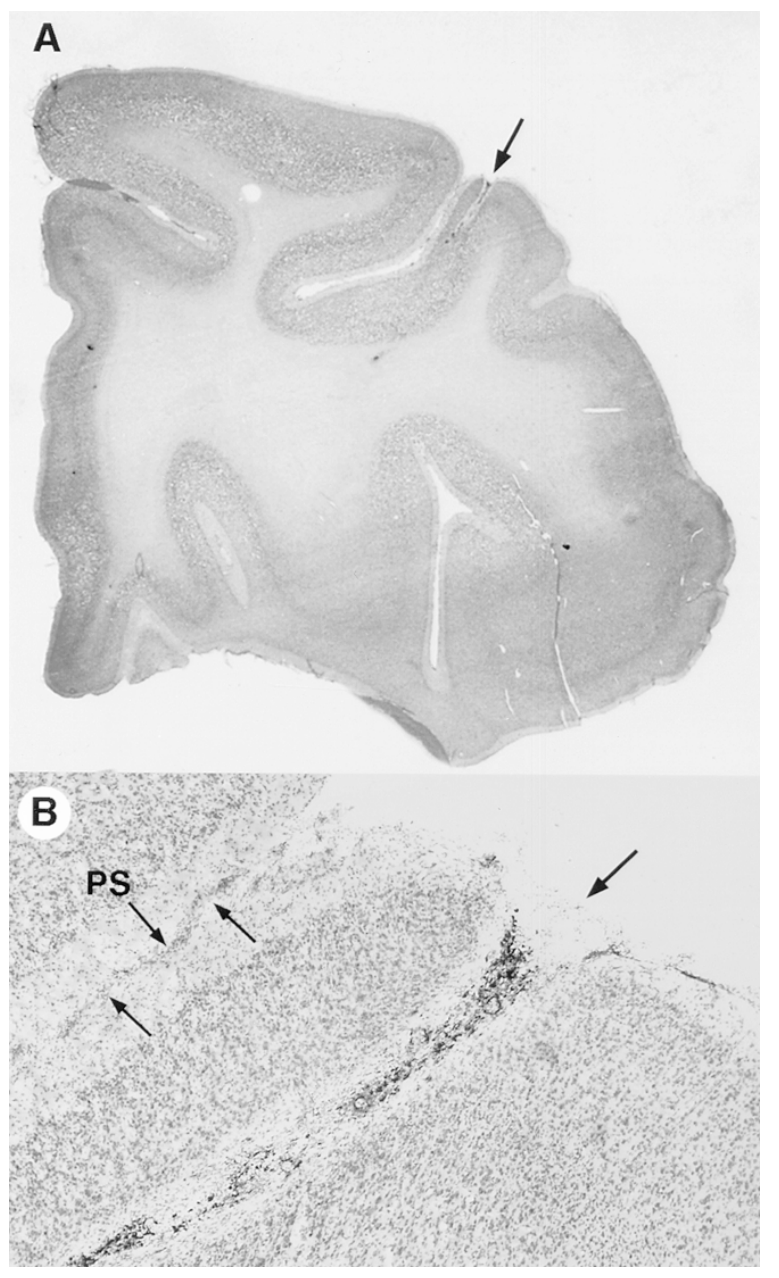

Figure 1. (A) A coronal section (40 $\mu \mathrm{m}$ thickness) of the rhesus monkey brain showing a microdialysis probe track extending into the ventral bank of the principal sulcus. The section has been stained with cresyl violet. (B) A magnified view of the track $(\times 40)$ shows the probe placement within the bank of the sulcus.

peated measures ANOVA was used to compare levels in response to drug administration. A $p$ value of $\leq .05$ was taken to be significant. To compare the cumulative effects of drugs across the 2-h sampling period (\% area under the curve), the Mann-Whitney U-test was used. For comparison purposes, data are presented as a percentage of the mean of three consecutive basal values collected immediately preceding drug administration.

\section{RESULTS}

\section{Baseline Dopamine Concentrations}

Basal extracellular concentrations of dopamine were measured reliably in the caudate nucleus, the putamen, and in several frontal cortical regions, including the dorsolateral prefrontal cortex (Walker's area 46, princi- pal sulcus), medial prefrontal cortex (Walker's areas 8 and 9), and premotor cortex (Walker's area 6). Table 1 shows the basal concentrations of dopamine in dialysate for these discrete brain regions during those experiments in which measurable baseline was obtained. These basal levels constitute the sum results from the current studies as well as other drug studies conducted in the same animals. Dialysate concentrations of dopamine ranged from 0.11 to $0.15 \mathrm{fmole} / \mu \mathrm{L}$ in the cortical regions (Table 1), whereas these levels were much higher in the caudate nucleus and the putamen, at 1.10 and $1.30 \mathrm{fmole} / \mu \mathrm{L}$, respectively.

\section{Effect of Systemic Clozapine and Haloperidol on Dopamine Release}

Clozapine and haloperidol were injected 3-4 h after probe implantation. As illustrated in Figure 3A, $2.0 \mathrm{mg} /$ $\mathrm{kg}$ I.V. clozapine produced a significant and long-lasting increase in extracellular dopamine to nearly $225 \%$ of baseline levels in the principal sulcus $\left(\mathrm{F}_{(10,88)}=4.74\right.$, $p<.001)$. Posthoc comparison of the data demonstrated that this increase remained significantly above baseline concentrations $2 \mathrm{~h}$ after drug injection, at which time the experiment was terminated. Clozapine also produced a significant increase in extracellular dopamine to $170 \%$ of baseline levels in the caudate nucleus $\left(\mathrm{F}_{(8,72)}=\right.$ $12.02, p<.001$, Figure 3B) that remained elevated above baseline for the duration of the experiment. A comparison of the effects of clozapine in the principal sulcus and caudate by two-way repeated measures ANOVA indicated that clozapine increased extracellular dopamine levels to a greater degree in the principal sulcus than in the caudate nucleus $\left(\mathrm{F}_{(5,90)}=2.53, p<.05\right)$. On a few occasions, sampling continued for $3-4 \mathrm{~h}$ after drug injection. On these occasions, the elevated concentrations of dopamine in both the principal sulcus and the caudate nucleus returned to levels at or near predrug baseline. There was no significant increase in dopamine release in response to clozapine in both medial prefrontal cortex (Figure 4A, areas 8 and 9) and premotor cortex (Figure 4B, area 6). This is most likely due to the limited sampling groups for these two regions. All of the clozapine response data are taken from repeated sampling in three subjects. No inconsistencies in the responses of extracellular dopamine concentration to clozapine administration were found within individual subjects over time.

The effect of haloperidol $(0.5 \mathrm{mg} / \mathrm{kg}$ IV) on dopamine release in the principal sulcus was assessed during three separate experiments where reliable baseline dopamine was detected. As can be seen in Figure 5A, haloperidol produced highly variable results in this region. In the caudate nucleus, haloperidol produced a significant increase in the extracellular concentration of dopamine $\left(\mathrm{F}_{(4,40)}=2.27, p<.05\right)$, which lasted for $1 \mathrm{~h}$ 

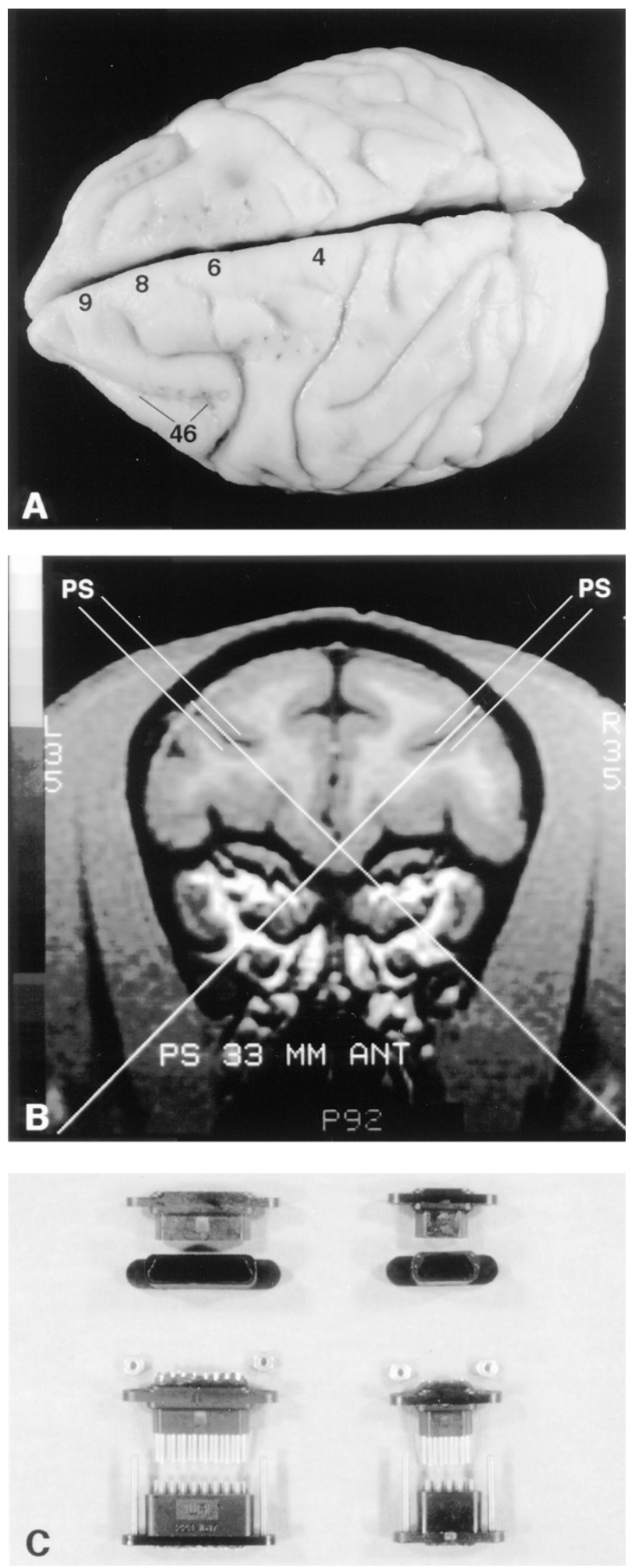

Figure 2. (A) The exterior of the brain from one subject. The black dots aligned in parallel rows over the surface of the cortex represent the locations of cannula/probe implantation sites. (B) A coronal MR image shows how the two banks of the principal sulcus were targeted for cannula implantation. (C) Guide cannula assemblies consisted of 19 gauge thin-wall stainless steel tubing glued into the base of black nylon plug/receptacle assemblies. Each base provided
Table 1. Basal Dopamine Release in Rhesus Monkey Brain

\begin{tabular}{lc}
\hline Brain Region & $\begin{array}{c}\text { Dopamine Level } \\
\text { (fmole/ } \mu \mathbf{l})\end{array}$ \\
\hline Putamen $(n=11)$ & $1.30 \pm 0.22$ \\
Caudate $(n=27)$ & $1.10 \pm 0.14$ \\
Medial prefrontal cortex (areas 8,$9 ; n=7)$ & $0.15 \pm 0.02$ \\
Premotor cortex (area $6 ; n=10)$ & $0.13 \pm 0.01$ \\
Principal sulcus (area $46 ; n=26)$ & $0.11 \pm 0.01$ \\
\hline
\end{tabular}

Values have not been corrected for in vitro recovery and are the means \pm SEM of three consecutive samples.

following drug administration (Figure 5B). The haloperidol response data are taken from repeated sampling in two subjects (principal sulcus) or three subjects (caudate nucleus). No inconsistencies in the responses of extracellular dopamine concentration in the caudate nucleus to haloperidol administration were found within individual subjects over time.

Figure 6 illustrates the cumulative increase in dopamine above baseline concentrations (\% area under the curve) for the 2-h sampling period following drug administration. As apparent from this analysis, clozapine, but not haloperidol, had a profound effect in the principal sulcus, whereas both haloperidol and clozapine, at the doses tested, increased dopamine release in the caudate nucleus.

\section{DISCUSSION}

\section{Assessment of Baseline Extracellular Dopamine}

This is the first report of measures of extracellular levels of dopamine in discrete regions of the prefrontal and frontal cortices in a chronic preparation of a nonhuman primate. The resting basal levels of dopamine measured in these regions show a rough correspondence to the differing levels of dopaminergic innervation of the frontal cortex (Williams and Goldman-Rakic 1993). Given that probe placements in the premotor cortex (area 6) were located more laterally (6d) than medially, extracellular concentrations of dopamine in medial prefrontal cortex (areas $8 \mathrm{~m}$ and $9 \mathrm{~m}$ ) were higher than in the premotor cortex. We found the lowest levels of dopamine in the principal sulcus (area 46). Our mea-

two parallel rows of cannulae. These cannula assemblies were outfitted with removable nylon tops with 23 gauge stainless steel wire stylets (22 $\mathrm{mm}$ length) glued in place. The larger assembly (left) was used bilaterally to target more medial structures, such as the medial prefrontal and premotor cortices, as well as the caudate nucleus and the putamen. The smaller assembly (right) was used bilaterally to target the principal sulcus. 
A
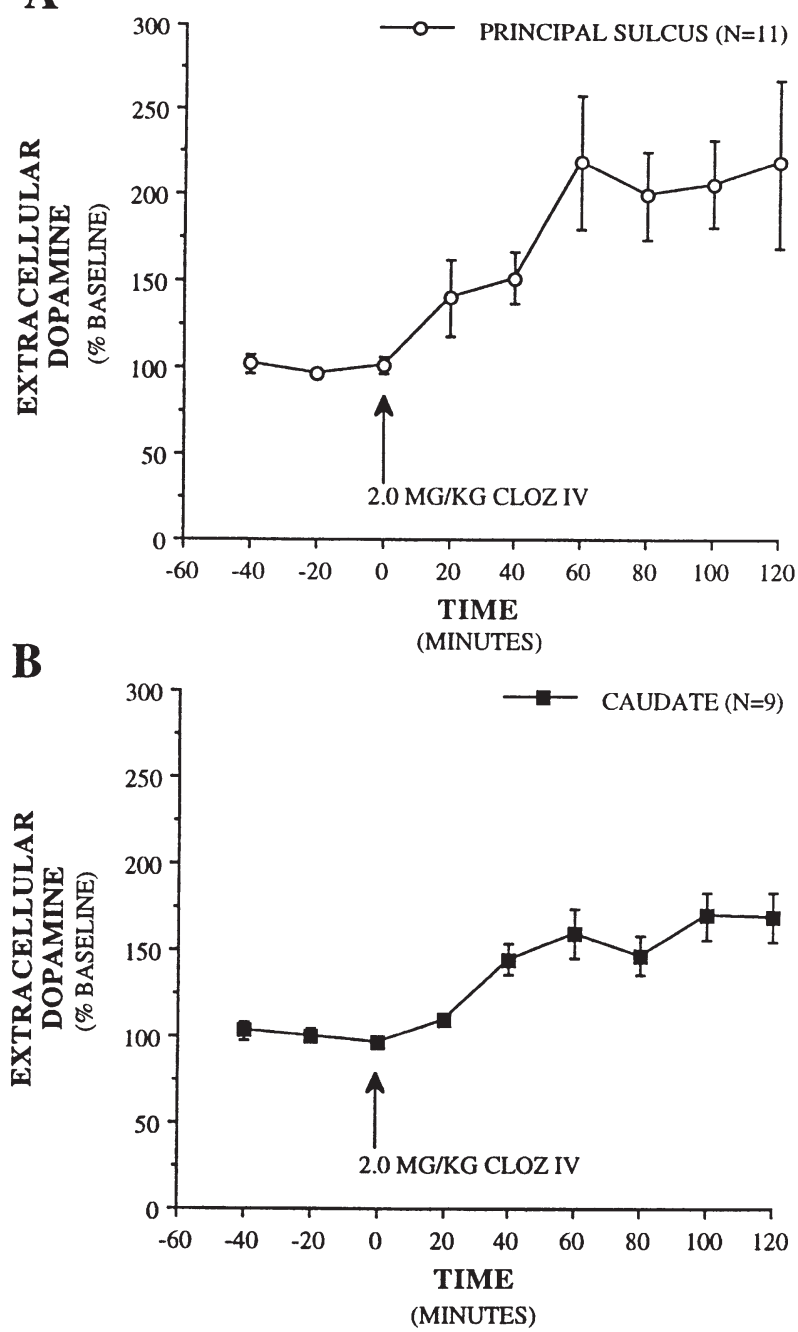

Figure 3. (A) Clozapine $(2.0 \mathrm{mg} / \mathrm{kg}$ IV) produced a significant and long-lasting increase $(p<.001)$ in extracellular dopamine levels in the principal sulcus. (B) Clozapine (2.0 $\mathrm{mg} / \mathrm{kg}$ IV) also produced a significant and long-lasting increase $(p<.001)$ in extracellular dopamine levels in the caudate. Clozapine had a significantly greater effect on extracellular dopamine levels in the principal sulcus than in the caudate $(p<.05)$. The clozapine response data are taken from repeated sampling in three subjects.

sures of extracellular dopamine followed this order: $8 \mathrm{~m}$ and $9 \mathrm{~m}>6 \mathrm{~d}>46$. As expected, extracellular concentration of dopamine was much greater in the caudate and putamen than in the cortical regions.

\section{Differential Effects of Clozapine in Cortex and Striatum}

The present results show that the atypical antipsychotic drug, clozapine, exerts preferential effects on dopamine release in the principal sulcus of the rhesus monkey in comparison to the caudate nucleus. These results com-
A

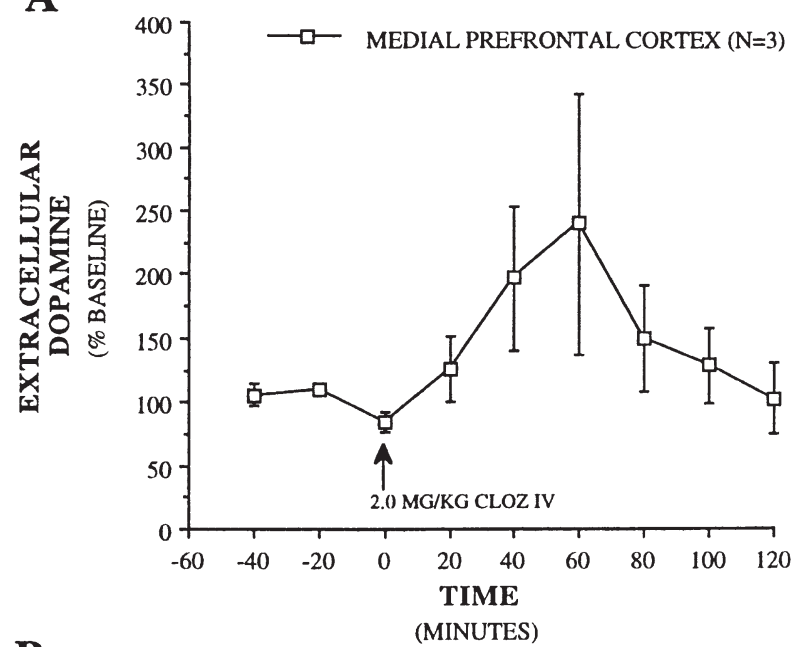

$\mathbf{B}$

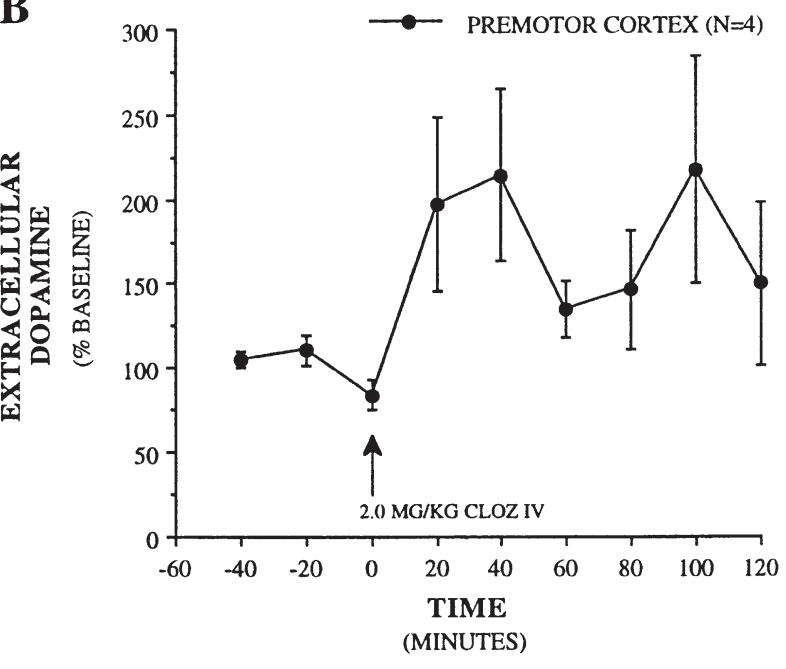

Figure 4. (A) Clozapine (2.0 mg/kg IV) produced no significant increase in dopamine release in the medial prefrontal cortex (areas 8 and 9, $p=.11$ ). (B) A similar result was seen in the premotor cortex (area $6, p=.11$ ). The clozapine response data are taken from repeated sampling in three subjects.

plement those studies done in the rodent, in which acute clozapine administration has been shown to produce greater increases in dopamine release in prefrontal cortex than in subcortical areas (Moghaddam and Bunney 1990; Pehek et al. 1993). Furthermore, studies in the rodent have demonstrated that the increase in dopaminergic output persists with chronic clozapine treatment, in that resting basal levels of dopamine are elevated in the prefrontal cortex, but not in subcortical regions, in response to chronic clozapine administration (Yamamoto and Cooperman 1994; Youngren et al. 1994). Taken together, the above findings suggest that activation of dopamine release in the prefrontal cortex might be an important component in the effectiveness of clozapine treatment. In comparing results in the 


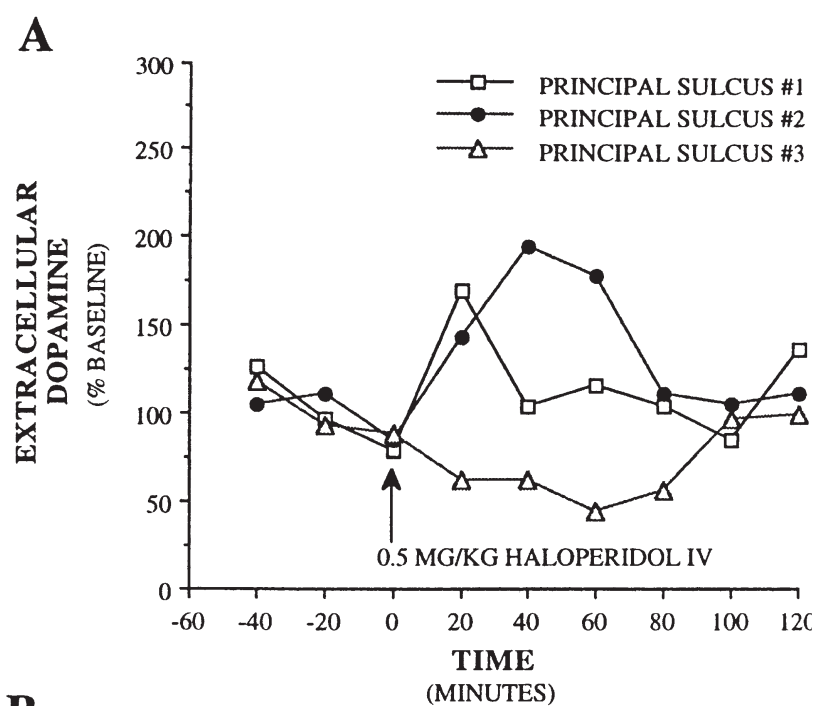

B

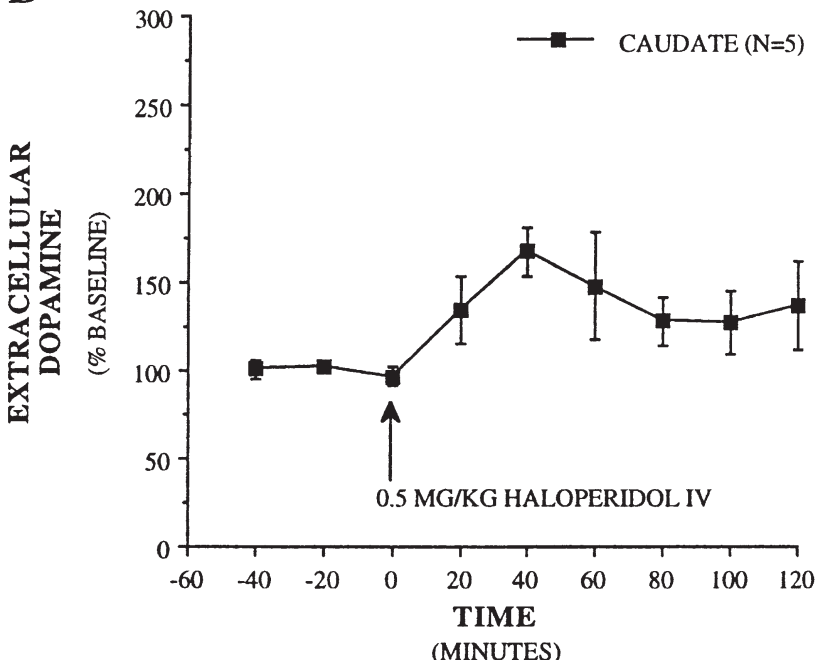

Figure 5. (A) Haloperidol (0.5 $\mathrm{mg} / \mathrm{kg}$ IV) produced inconsistent effects on extracellular dopamine levels in three separate experiments performed in the principal sulcus. (B) Haloperidol $(0.5 \mathrm{mg} / \mathrm{kg}$ IV) produced a significant increase $(p<.05)$ in extracellular dopamine levels in the caudate nucleus. The haloperidol response data are taken from repeated sampling in two subjects (principal sulcus) or three subjects (caudate nucleus).

monkey with those in the rodent, it is useful to consider possible homology between cortical regions of the two species. Functionally, the integrity of both the rat medial prefrontal cortex and the monkey dorsolateral prefrontal cortex is necessary for proper functioning of spatial working memory in the two species. Although the rat medial prefrontal cortex can be said to share some anatomical characteristics with the dorsolateral and medial prefrontal (as well as premotor) cortices of the monkey, clearly these areas become more specialized and elaborate in the monkey. Due to a lack of segregation of function in the rat medial prefrontal cortex,

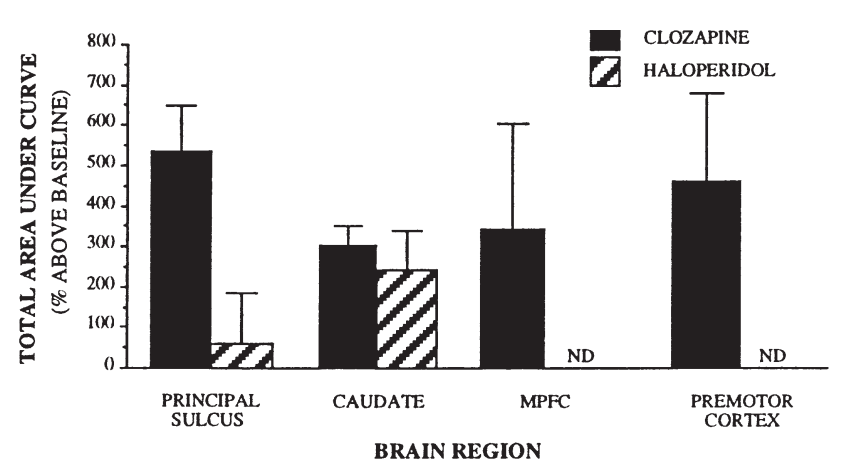

Figure 6. Cumulative increase in dopamine above baseline levels ( $\%$ area under the curve) for the 2-h sampling period following drug administration. $\mathrm{ND}=$ not done.

it is therefore difficult to posit direct homology of cortical regions between the rat and primate [see Uylings and van Eden (1990) for review].

An important issue remains: the mechanism by which clozapine exerts a preferential effect on extracellular dopamine concentrations in the prefrontal cortex compared to the caudate nucleus or striatum. A recent study of the regulatory effect of chronic antipsychotic drug treatment on dopamine receptors in rhesus monkeys has shown that clozapine is capable of upregulating cortical $\mathrm{D}_{2}$ receptors (Lidow and Goldman-Rakic 1994) and $D_{2}$ mRNAs, although it has little effect on $D_{2}$ receptor mRNAs in the striatum (Lidow et al. 1997). However, considering the different profile observed with the $\mathrm{D}_{2}$ antagonist haloperidol, it is more likely that other receptors for which clozapine has moderate to high affinity (Ashby and Wang 1996) are responsible for clozapine's cortical dopamine effects.

A possible mechanism that may contribute to clozapine's stimulatory effects on prefrontal cortex dopamine involves activation of $5-\mathrm{HT}_{1 \mathrm{~A}}$ receptors. Clozapine is a relatively potent partial $5-\mathrm{HT}_{1 \mathrm{~A}}$ agonist, and pretreatment with the selective 5- $\mathrm{HT}_{1 \mathrm{~A}}$ antagonist WAY 100635 reduces the increase in rat cortical dopamine release caused by clozapine (Rollema et al. 1997). This mechanism is consistent with preferential activation of dopamine turnover in the rat prefrontal cortex by $5-\mathrm{HT}_{1 \mathrm{~A}}$ agonists (Rasmusson et al. 1994).

Recent data have suggested that blockade of $5-\mathrm{HT}_{2 \mathrm{~A}}$ receptors may also contribute to clozapine's effects in the prefrontal cortex. The $5-\mathrm{HT}_{2 \mathrm{~A}}$ receptor antagonists MDL 100907, amperozide, and ritanserin preferentially increase dopamine release in the prefrontal cortex in comparison to the striatum when given systemically or infused locally into the prefrontal cortex in the rodent (Pehek et al. 1993; Schmidt and Fadayel 1995; Pehek 1996). The recent anatomical localization of $5-\mathrm{HT}_{2 \mathrm{~A}}$ receptors to both pyramidal neurons and to a subset of GABAergic interneurons in the primate (Jakab and Goldman-Rakic 1998), and the physiological involve- 
ment of this receptor in neurons engaged in working memory processes (Williams et al. 1996) make this possibility very intriguing.

Another related mechanism that may play a role in clozapine's preferential effects on prefrontal cortex dopamine may involve the convergence of $5-\mathrm{HT}_{2 \mathrm{~A}}$ and $\mathrm{D}_{4}$ inputs to the GABAergic interneurons of the cortex (Mrzljak et al. 1996). Blockade of 5- $\mathrm{HT}_{2 \mathrm{~A}}$ and $\mathrm{D}_{4}$ receptors by clozapine may produce a synergistic effect to reduce the activity of cortical GABA neurons. This will result in feedforward disinhibition of cortical pyramidal neurons and enhancement of glutamatergic transmission both within the prefrontal cortex and in targets of prefrontal cortex neurons, such as the ventral tegmental area. Indeed, clozapine decreases GABA release (Bourdelais and Deutch 1994) and increases glutamate efflux (Daly and Moghaddam 1993; Yamamoto and Cooperman 1994) in the prefrontal cortex.

\section{Effects of Haloperidol}

The present study demonstrates that haloperidol increases dopamine release in the caudate nucleus in a manner somewhat comparable to clozapine. However, haloperidol did not produce a consistent effect on cortical release of dopamine. The stimulation of dopamine release seen in the caudate nucleus is in agreement with a number of studies in the rodent in which haloperidol increased extracellular dopamine concentrations in dorsal and ventral striatal regions (Moghaddam and Bunney 1990; Yamamoto and Cooperman 1994). Based on the current data, however, it cannot be said whether haloperidol produces a preferential effect on extracellular concentrations of dopamine in primate cortical or subcortical regions. Nevertheless, the lack of a consistent effect of haloperidol in the principal sulcus suggests that while shared pharmacological characteristics between haloperidol and clozapine, such as blockade of dopamine $D_{2}$ receptors, may account for increased dopamine release in the caudate, blockade of other receptors for which clozapine, but not haloperidol, has affinity are responsible for the dopamine release-activating effects of clozapine in the principal sulcus.

\section{CONCLUSIONS}

Considering that clozapine occupies only a subset (e.g., $\mathrm{D}_{4}>\mathrm{D}_{1}$ ) of dopamine receptors in the prefrontal cortex at therapeutic doses (Seeman 1992), clozapine administration may not result in appreciable postsynaptic blockade of dopaminergic neurotransmission within the cortex. The net effect of the preferential increase in dopamine release produced by clozapine in the principal sulcus of the primate would thus be an activation of cortical dopamine neurotransmission. It has been suggested that prefrontal cortical dopamine dysfunction may underlie some of the symptomatology of schizophrenia (Weinberger et al. 1986; Davis et al. 1991; Jentsch et al. 1997). Therefore, clozapine may exert its unique therapeutic effects, in part, by counteracting a dopaminergic deficit in the prefrontal cortex.

Clozapine also potentiated dopamine release in the caudate nucleus; however, studies in the rodent have suggested that, upon chronic treatment with clozapine, enhancement of dopamine output is maintained only in the prefrontal cortex and not in subcortical regions (Yamamoto and Cooperman 1994; Youngren et al. 1994). A sustained increase in cortical dopaminergic transmission may have crucial implications for activity in subcortical dopaminergic terminal field regions, such as the caudate nucleus and nucleus accumbens. Recent studies have shown that the prefrontal cortex regulates subcortical dopamine release in the rodent (Taber et al. 1995; Karreman and Moghaddam 1996), and increased dopaminergic activity in the prefrontal cortex of primates and rodents reduces dopamine release in the striatum (Kolachana et al. 1995; Karreman and Moghaddam 1996; Saunders et al. 1998). Therefore, sustained augmentation of prefrontal cortical dopamine neurotransmission by clozapine may normalize the hyperdopaminergic state postulated to be present in subcortical areas in schizophrenia. Through these concomitant effects, clozapine may alleviate the symptomatology of schizophrenia without the production of side effects common to typical antipsychotic drug therapies.

In summary, the present study demonstrates that, in the nonhuman primate, the atypical antipsychotic drug clozapine exerts preferential effects on dopamine release in the prefrontal cortex. These results provide support for the idea that clozapine exerts its therapeutic effects in part by increasing dopaminergic neurotransmission in the prefrontal cortex.

\section{ACKNOWLEDGMENTS}

We thank Terri Beattie for expert technical assistance and Dr. Nicolas Hengartner (Dept. of Statistics, Yale University) for assistance in analyzing data. Support for these studies came from National Institutes of Health grants MH44866, MH48404, and MH14092.

\section{REFERENCES}

Ashby CR, Jr , Wang RY (1996): Pharmacological actions of the atypical antipsychotic drug clozapine: a review. Synapse 24:349-394

Berger B, Casper P, Verney C (1991): Dopaminergic innervation of the cerebral cortex: unexpected differences between rodents and primates. TINS 14:21-27 
Bourdelais AJ, Deutch AY (1994): The effects of haloperidol and clozapine on extracellular GABA levels in the prefrontal cortex of the rat: an in vivo microdialysis study. Cereb Cortex 4:69-77

Creese I, Burt DR, Snyder SH (1977): Dopamine receptor binding enhancement accompanies lesion-induced behavioral supersensitivity. Science 197:596-598

Daly DA, Moghaddam B (1993): Actions of clozapine and haloperidol on the extracellular levels of excitatory amino acids in the prefrontal cortex and striatum of conscious rats. Neurosci Lett 152:61-64

Davis KL, Kahn RS, Ko G, Davidson M (1991): Dopamine in schizophrenia: a review and reconceptualization. Am J Psychiatry 148:1474-1486

Jakab RL, Goldman-Rakic PS (1998): 5-hydroxytryptamine(2A) serotonin receptors in the primate cerebral cortex-possible site of action of hallucinogenic and antipsychotic drugs in pyramidal cell apical dendrites. Proc Natl Acad Sci 95:735-740

Jentsch JD, Redmond Jr DE, Elsworth JD, Taylor JR, Youngren KD, Roth RH (1997): Enduring cognitive deficits and cortical dopamine dysfunction in monkeys after longterm administration of phencyclidine. Science 277:953-955

Kane J, Honigfeld G, Singer J, Meltzer H (1988): Clozapine for the treatment-resistant schizophrenic. A doubleblind comparison with chlorpromazine. Arch Gen Psychiatry 45:789-796

Kane JM, Woerner MG, Pollack S, Safferman AZ, Lieberman JA (1993): Does clozapine cause tardive dyskinesia? J Clin Psychiatry 54:327-330

Karreman M, Moghaddam B (1996): The prefrontal cortex regulates the basal release of dopamine in the limbic striatum: an effect mediated by ventral tegmental area. J Neurochem 66:589-598

Kolachana BS, Saunders RC, Weinberger DR (1994): An improved methodology for routine in vivo microdialysis in non-human primates. J Neurosci Methods 55:1-6

Kolachana BS, Saunders RC, Weinberger DR (1995): Augmentation of prefrontal cortical monoaminergic activity inhibits dopamine release in the caudate nucleus: an in vivo neurochemical assessment in the rhesus monkey. Neuroscience 69:859-868

Lee MA, Thompson PA, Meltzer HY (1994): Effects of clozapine on cognitive function in schizophrenia. J Clin Psychiatry 55:82-87

Lidow MS, Elsworth J, Goldman-Rakic PS (1997): Downregulation of the D1 and D5 dopamine receptors in the primate prefrontal cortex by chronic treatment with antipsychotic drugs. J Pharmacol Exp Ther 281:597-603

Lidow MS, Goldman-Rakic PS (1994): A common action of clozapine, haloperidol, and remoxipride on D1- and D2dopaminergic receptors in the primate cerebral cortex. Proc Natl Acad Sci USA 91:4353-4356

Machida CA, Searles RP, Nipper V, Brown JA, Kozell LB, Neve KA (1992): Molecular cloning and expression of the rhesus macaque D1 dopamine receptor gene. Mol Pharmacol 41:652-659

Moghaddam B, Berridge CW, Goldman-Rakic PS, Bunney BS, Roth RH (1993): In vivo assessment of basal and druginduced dopamine release in cortical and subcortical regions of the anesthetized primate. Synapse 13:215-222
Moghaddam B, Bunney BS (1990): Acute effects of typical and atypical antipsychotic drugs on the release of dopamine from prefrontal cortex, nucleus accumbens, and striatum of the rat: an in vivo microdialysis study. J Neurochem 54:1755-1760

Mrzljak L, Bergson C, Pappy M, Huff R, Levenson R, Goldman-Rakic PS (1996): Localization of dopamine D4 receptors in GABAergic neurons of the primate brain. Nature 381:245-248

Pehek EA (1996): Local infusion of the serotonin antagonists ritanserin or ICS 205,930 increases in vivo dopamine release in the rat medial prefrontal cortex. Synapse 24:12-18

Pehek EA, Meltzer HY, Yamamoto BK (1993): The atypical antipsychotic drug amperozide enhances rat cortical and striatal dopamine efflux. Eur J Pharmacol 240:107109

Preuss TM, Goldman-Rakic PS (1991): Ipsilateral cortical connections of granular frontal cortex in the strepsirhine primate Galago, with comparative comments on anthropoid primates. J Comp Neurol 310:507-549

Rasmusson AM, Goldstein LE, Deutch AY, Bunney BS, Roth $\mathrm{RH}$ (1994): 5- $\mathrm{HT}_{1 \mathrm{a}}$ agonist $\pm 8-\mathrm{OH}-\mathrm{DPAT}$ modulates basal and stress-induced changes in medial prefrontal cortical dopamine. Synapse 18:218-224

Rollema H, Lu Y, Schmidt AW, Zorn SH (1997): Clozapine increases dopamine release in prefrontal cortex by 5-HT1A receptor activation. Eur J Pharmacol 338:R3-5

Saunders RC, Kolachana BS, Bachevalier J, Weinberger DR (1998): Neonatal lesions of the medial temporal lobe disrupt prefrontal cortical regulation of striatal dopamine. Nature 393:169-171

Schmidt CJ, Fadayel GM (1995): The selective 5-HT2A receptor antagonist, MDL 100,907, increases dopamine efflux in the prefrontal cortex of the rat. Eur J Pharmacol 273:273-279

Seeman P, Lee T, Chau-Wong M, Tedesco J, Wong K (1976): Antipsychotic drug doses and neuroleptic/dopamine receptors. Nature 261:717-719

Seeman P (1992): Dopamine receptor sequences. Therapeutic levels of neuroleptics occupy D2 receptors, clozapine occupies D4. Neuropsychopharmacol 7:261-284

Taber MT, Das S, Fibiger HC (1995): Cortical regulation of subcortical dopamine release: mediation via the ventral tegmental area. J Neurochem 65:1407-1410

Uylings HBM, van Eden CG (1990): Qualitative and quantitative comparison of the prefrontal cortex in rat and in primates, including humans. In Uylings HBM, van Eden CG, De Bruin JPC, Corner MA, Feenstra MGP (eds), Progress in Brain Research, Vol 85. Amsterdam: Elsevier, pp 31-62

van Tol HH, Bunzow JR, Guan H-C, Sunahara RK, Seeman P, Niznik HB, Civelli O (1991): Cloning of the gene for a human dopamine D4 receptor with high affinity for the antipsychotic clozapine. Nature 350:610-614

Wang J, Skirboll S, Aigner TG, Saunders RC, Hsiao J, Bankiewicz KS (1990): Methodology of microdialysis of neostriatum in hemiparkinsonian nonhuman primates. Exp Neurol 110:181-186

Weinberger DR, Berman KF, Zec RF (1986): Physiologic dys- 
function of dorsolateral prefrontal cortex in schizophrenia. I. Regional cerebral blood flow evidence. Arch Gen Psychiatry 43:114-124

Williams GV, Rao SG, Franowitz M, Romanski L, GoldmanRakic PS (1996): Ritanserin reduces activity of prefrontal pyramidal neurons recorded during working memory tasks. Soc Neurosci Abstr 22:1936

Williams SM, Goldman-Rakic PS (1993): Characterization of the dopaminergic innervation of the primate frontal cor- tex using a dopamine-specific antibody. Cereb Cortex 3:199-222

Yamamoto BK, Cooperman MA (1994): Differential effects of chronic antipsychotic drug treatment on extracellular glutamate and dopamine concentrations. J Neurosci 14:4159-4166

Youngren KD, Moghaddam B, Bunney BS, Roth RH (1994): Preferential activation of dopamine overflow in prefrontal cortex produced by chronic clozapine treatment. Neurosci Lett 165:41-44 